\title{
A gestão de design de micro e pequenas empresas desenvolvedoras de produtos com foco em sustentabilidade
}

Design management in micro and small enterprises that focus on sustainable products

Fabiane Wolff

Universidade do Vale do Rio dos Sinos - Unisinos

fabiwolff@unisinos.br

Pedro Rafael Geremias Benites

Centro Universitário Ritter dos Reis - UniRitter

benites.pedro@gmail.com

at

PROJËTICA

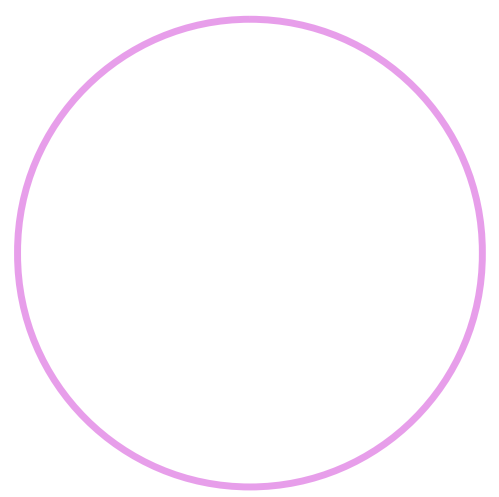

COMO CITAR ESTE ARTIGO:

WOLFF, F.; BENITES, P. R. G. A gestão de design de micro e pequenas empresas desenvolvedoras de produtos com foco em sustentabilidade. Projética, Londrina, v. 11, n. 1, p 164-193, 2020.

DOI: 10.5433/2236-2207.2020v11n1p164

Submissão: 10-07-2018

Aceite: 01-07-2019

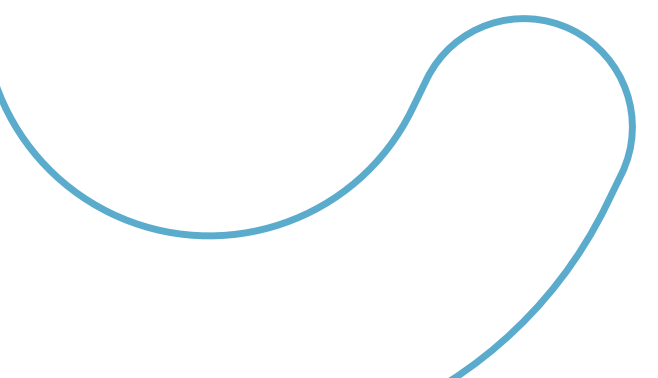


A gestão de design de micro e pequenas empresas... sustentabilidade WOLFF, F.; BENITES, P. R. G.

RESUMO: Buscando compreender como se dá a Gestão de Design em empresas com foco na sustentabilidade, o presente artigo, através de uma abordagem exploratória, avalia como esta é entendida e estabelece um comparativo sobre como o tema é abordado no campo teórico e na realidade prática destes empresários. Através de pesquisa exploratória qualitativa, com entrevistas em profundidade o tema é abordado. Os resultados apontam para boas perspectivas futuras na relação entre Gestão de Design e Sustentabilidade uma vez que as ferramentas de gestão bem estruturadas abrem caminho para os aspectos de sustentabilidade dentro das organizações.

Palavras-chave: Gestão de design. Sustentabilidade. Design estratégico. Estratégias para design.

ABSTRACT: Aiming to understand how Design Management takes place in companies with a focus on sustainability, this paper evaluates how such companies understand it. Through an exploratory approach, with in-depth interviews, we compare how the topic is approached in the theoretical field and in the daily practice of these enterprises. Results point to good future perspectives in the relationship between Design Management and Sustainability, since design management tools pave the way to sustainability within the corporate environment.

Keywords: Design Management. Sustainability. Strategic design. Design strategies.

\section{INTRODUÇÃO}

Os problemas financeiros vividos por países desenvolvidos, a competição global e os desafios gerados por problemas ambientais levaram a um contexto de negócios caracterizado por uma incerteza crescente. Nesse cenário, a inovação fazse necessária, sendo uma das alternativas de se lidar com esta crise (FIXSON; READ, 
Projética, Londrina, v.11, n.1, p. 164-193, abril 2020

2012). É através da inovação que as empresas terão a capacidade de identificar, formular e explorar novas oportunidades para produtos, serviços e modelos de negócios.

Para Borja de Mozota (2003, p. 116) “a imaginação é o novo combustível das empresas", sendo ideias a base da inovação, preferencialmente integrada à estratégia. Neste contexto, onde o papel da ciência na inovação tende a diminuir, um novo poder é concedido a indivíduos com perfis não convencionais como os designers., que fomentam a imaginação e podem gerar ideias em todas as etapas do processo de inovação.

Trummer e Lleras (2012) fortalecem esta visão ao afirmarem que o design é visto como um agente de mudança para a sociedade e um importante direcionador de inovação que gera valor à economia. Por conta disso, os designers são chamados a solucionar problemas em uma escala muito mais ampla atualmente. Borja de Mozota (2003) avança na questão ao dizer que o design já é considerado uma ferramenta de gestão e não mais apenas como algo relacionado a forma dos produtos. Sendo assim, o design é encarado com um "processo criativo de gestão que pode ser integrado em outros processos da organização, como gestão de design, de inovação e de pesquisa e desenvolvimento". O papel do designer neste contexto não é mais de autor, mas sim de facilitador ou estrategista. Conforme apontam Trummer e Lleras (2012), ao longo do último século o valor do design foi do fazer, ao projetar e chega agora ao planejar.

O atual cenário de como são produzidos, distribuídos e consumidos os produtos sugere uma perspectiva pessimista com relação ao futuro do planeta. A preocupação com sustentabilidade ainda não é uma realidade absoluta no contexto empresarial e passou-se a viver em uma sociedade onde o grau de satisfação é medido através do grau de consumo e uma parcela da culpa por isto ter acontecido é, sim, dos designers, sustenta Vezzoli (2010). 


\section{A gestão de design de micro e pequenas empresas... sustentabilidade}

WOLFF, F.; BENITES, P. R. G.

O principal desafio reside no fato de a sociedade atual basear-se em um sistema de desenvolvimento que nos últimos 200 anos ofereceu avanços em eficiência técnica, produtividade industrial e elevou o padrão de vida e de conforto ao redor do mundo. Entretanto, este mesmo sistema começa a apresentar prejuízos na mesma velocidade em que gera benefícios.

Neste padrão de desenvolvimento, que faz com que o progresso seja medido em termos de crescimento econômico, há também a tendência de desvalorização do ato humano com o oferecimento de soluções relacionadas à tecnologia e à automação de processos. Este é o resultado de um modelo de desenvolvimento equivocado sob a ótica da sustentabilidade. Neste cenário, onde uma transformação profunda faz-se necessária, evoca-se o poder do design como transformador de sistemas físicos, sociais e econômicos que constituem nossa relação com o mundo que nos cerca. Estes problemas apresentam desafios sistemáticos, portanto deve-se oferecer a eles soluções do mesmo tipo.

Apesar de considerados parte do problema, os designers carregam em si também parte da solução. São estes os profissionais que estarão mais adaptados a lidar com o cenário difuso e interdisciplinar que proporcionará uma mudança de consciência na forma como se consome e se vive, para a partir de então pensarse em uma mudança radical em nossa sociedade visando o desenvolvimento sustentável e a preservação da vida humana no planeta.

Thackara (2008, p. 21) afirma que "Nessa nova era de inovação colaborativa, os designers estão tendo de evoluir de autores individuais de objetos, a facilitadores da mudança entre grandes grupos de pessoas". Esta transição é caracterizada pela crescente valorização da Gestão de Design entre as empresas. Por apresentar um perfil multidisciplinar e agregador, o designer torna-se um espécie de tradutor dentro de uma equipe. Neste contexto é possível dizer que um processo de design voltado para a sustentabilidade necessita da participação de todos os atores 
Projética, Londrina, v.11, n.1, p. 164-193, abril 2020

envolvidos no desenvolvimento de produtos de uma organização, e não apenas a dos designers. Sendo assim, empresas cujas estratégias estão baseadas na orientação para a sustentabilidade devem trabalhar sua gestão de design sob esta perspectiva em todos os seus níveis organizacionais.

O aumento de consciência de empresários com relação à questão da sustentabilidade é refletido também no caso das micro e pequenas empresas. A crescente conscientização neste setor apresenta-se como uma grande oportunidade para designers atuarem estrategicamente a fim de gerar resultados sob este aspecto mercadológico. Dessa forma a gestão de design ganha destaque como forma de gerenciar estes esforços rumo ao desenvolvimento sustentável também neste setor.

A partir desta possibilidade, surge o questionamento sobre como acontece o processo de gestão de design neste novo cenário de micro e pequenos negócios orientados para sustentabilidade. Assim sendo, tem-se como objetivo avaliar como se dá a inserção da gestão de design em micro e pequenas empresas, desenvolvedoras de produtos, com foco em sustentabilidade. Através de uma pesquisa qualitativa e um instrumento de avaliação, designers foram entrevistados e os resultados são apresentados e discutidos neste artigo.

\section{OBJETIVOS E MÉTODO}

Este trabalho apresenta uma abordagem de pesquisa exploratória, aplicada (GIL, 1999). Dessa forma, busca-se a compreensão do contexto de como se dá a Gestão de Design em micro e pequenas empresas desenvolvedoras de produtos com foco em sustentabilidade através da análise de empresas de micro e pequeno porte locais. Entre os procedimentos utilizados neste trabalho estão a pesquisa bibliográfica, para sustentar conhecimentos e proporcionar base para análise, e a pesquisa de campo. 


\section{A gestão de design de micro e pequenas empresas... sustentabilidade \\ WOLFF, F.; BENITES, P. R. G.}

A amostra, não probabilística e intencional, teve como elemento as micro e pequenas empresas, em um universo de empresas desenvolvedoras de produtos com foco em sustentabilidade, enquanto a população é referente às micro e pequenas empresas desenvolvedoras de produtos de Porto Alegre e região metropolitana. Esta amostra é característica da pesquisa qualitativa, pequena e com resultados não generalizáveis, visando explorar um problema de pesquisa. A amostra composta por três empresas que atenderam a dois critérios básicos: se encaixar no perfil de micro ou pequena empresa, de acordo com o padrão de avaliação adotado pelo SEBRAE e demonstrar o foco na sustentabilidade através da utilização de recursos secundários (pré ou pós consumo) na etapa de pré-produção de seus produtos, ou seja, a utilização de matérias-primas oriundas de descartes e refugos de processos produtivos e atividades de consumo anteriores. A amostra é apresentada na Tabela 1, a seguir, resguardando as identidades das empresas segundo Termos de Consentimento Livres e Esclarecidos assinados pelas mesmas no processo 43060615.2.0000.5309, na Plataforma Brasil de Ética em Pesquisa.

Tabela 1 - Perfil da Amostra

\begin{tabular}{|c|c|c|c|}
\hline EMPRESA & ENTREVISTADO & CARGO & FORMAÇÃO \\
\hline EMPRESA A & Entrevistada 1 & Sócia-Diretora & Design de Produto \\
\hline EMPRESA B & Entrevistada 2 & Sócia-Diretora & Design de Produto \\
\hline EMPRESA C & Entrevistado 3 & Sócio-Diretor & Administração \\
\hline
\end{tabular}

Fonte: Elaborado pelos autores.

Para a coleta de campo, foram desenvolvidas entrevistas em profundidade, com roteiros semiestruturados operacionalizados em dois momentos: uma primeira rodada de questões acerca da realidade das empresas e do seu foco na sustentabilidade e (b) a avaliação da gestão de design da empresa. Este segundo ponto foi procedido através do instrumento de coleta de dados da Sistemática de 
Projética, Londrina, v.11, n.1, p. 164-193, abril 2020

Avaliação da Gestão de Design/SAGD (WOLFF, 2012), que visa analisar como se dá a Gestão de Design em empresas. O instrumento é composto por 30 variáveis divididas em três dimensões, processo, competência e estratégia. As variáveis visam identificar como são percebidas as características da Gestão de Design, conforme a tabela 2, abaixo. As variáveis são medidas com uma escala Likert de 7 pontos de concordância e, embora viabilizem uma medida quantitativa, devido aos objetivos e a pequena amostra desta pesquisa trazem resultados que são entendidos de modo qualitativo. Um ponto importante a ser salientado é que a SAGD não tem uma dimensão de sustentabilidade. Isso acontece porque é uma medida de Gestão de Design e não da sustentabilidade e si, e aqui é utilizada para compreender como a Gestão de Design se dá nas empresas com foco na sustentabilidade, ressaltando nosso foco de estudo.

No que diz respeito à forma como os dados coletados foram analisados, houveram duas etapas. A primeira consistia na análise de conteúdo dos dados coletados nas entrevistas semiestruturadas, onde analisados os dados a partir da análise das falas dos entrevistados. Esta análise de conteúdo seguiu os três passos de Bardin (2011), partindo da pré análise, feita na transcrição das entrevistas. O segundo passo, de exploração do material, compreende os momentos de codificação da coleta, classificação das falas e categorização dos conteúdos abordados. Por fim, há então o tratamento dos resultados, com a triangulação das evidências observadas como base para inferências e interpretações.

A análise da SAGD deu-se através da tabulação dos resultados obtidos no questionário para avaliar a intensidade de concordância geral com as variáveis propostas. A sobreposição das respostas de todos os entrevistados pode serinterpretada através das áreas mais escuras nos gráficos apresentados na análise como uma maior ocorrência de resultados similares que identificam alguns padrões de entendimento por parte da amostra analisada. 


\section{A gestão de design de micro e pequenas empresas... sustentabilidade \\ WOLFF, F.; BENITES, P. R. G.}

Tabela 2 - SAGD: Sistemática de Avaliação da Gestão de Design

\begin{tabular}{l} 
Processo \\
1. Utilizamos design, pois é um bom modo de organizar nossa produção. \\
2. O uso do design organizou nosso processo de desenvolvimento de produto \\
3. O uso do design visa resolver somente questões técnicas de produtos.* \\
4. Os processos de design estão integrados aos processos de nossa empresa. \\
\hline 5. Nós documentamos nossos processos de design e desenvolvimento de produto. \\
\hline 6. Em nossa empresa, temos um método organizado de desenvolver produtos. \\
\hline 7. Estimulamos a equipe de design de nossa empresa a utilizar métodos conhecidos de projeto. \\
\hline 8. A equipe de design deve seguir sempre o que foi primeiramente estabelecido pela equipe de \\
marketing.* \\
\hline 9. A equipe de design deve seguir sempre o que foi primeiramente estabelecido pela engenharia.* \\
\hline 10. A equipe de design está plenamente integrada às outras equipes que dão vida a nossa empresa. \\
11. As equipes de engenharia e marketing acham difícil trabalhar com equipes de design. \\
\hline 12. A equipe de design tem independência para criar novos produtos. \\
\hline
\end{tabular}

\section{Competência}

13. Pensamos que os designers são colaboradores importantes na empresa.

14. A função de design é mais importante para nossa empresa do que o trabalho do designer em si.

15. O designer chefe é consultado sempre que começamos a pensar no desenvolvimento de um novo produto.

16. Acreditamos ser possível ter um bom design mesmo que ninguém em nossa equipe seja formado especificamente em design.

17.Nossa equipe de design se atualiza frequentemente, em faculdades e cursos.

18. Nossa equipe de design se atualiza visitando feiras e exposições no exterior.

19. Os designers têm dificuldades em se integrar aos outros funcionários e departamentos da empresa. *

\section{Estratégia}

20. Os objetivos estratégicos de nossa empresa são traduzidos pelo design (ou - o design trabalha segundo os objetivos estratégicos desta empresa)

21. Nossa empresa entende o design como fator importante na inovação de produto

22. Design pode ser considerado como a lógica dominante em nossa empresa.

23. A lógica do design está espalhada pelos diferentes departamentos de nossa empresa.

24. O mais importante, no uso do design, é o estilo/estética que ele confere aos nossos produtos. *

25. As decisões de design em nossa empresa são tomadas somente pelos diretores.

26. Os diretores desta empresa acompanham de perto o trabalho dos designers, opinando e interferindo.

27. Fazemos reuniões periódicas, com as equipes envolvidas no projeto dos produtos para discuti-lo.

28. Em nossa empresa, design, engenharia, comercial e marketing trabalham juntos no desenvolvimento de produtos.

29. Design melhorou nossa performance empresarial.

30. Acreditamos que nosso lucro é maior em função do uso do design.

Fonte: Wolff (2012). 
Projética, Londrina, v.11, n.1, p. 164-193, abril 2020

A fase final de exploração do material, a categorização dos dados coletados nas entrevistas em profundidade, orienta toda a análise apresentada a seguir. Dividida entre as 6 categorias: perfil, processo de design, competência de design, estratégia de design, sustentabilidade e colaboração a análise apresenta e discute os resultados obtidos.

\section{ANÁLISE DOS RESULTADOS}

Quanto ao perfil da amostra, considerando as empresas apresentadas na tabela 1, pode se dizer que a empresa A foi criada em 2013, em Porto Alegre, por duas sócias de formações distintas, uma economista e uma bacharel em direito. Após o primeiro ano de existência, houve a inclusão de uma designer de produto, ainda em formação, à equipe. A empresa trabalha com artesãs de comunidades carentes para criar produtos que vão desde acessórios de armazenamento pessoal a mochilas e bolsas, através da utilização de materiais alternativos e reutilizados. Segundo as suas fundadoras, o objetivo principal do negócio é prover oportunidades para estas artesãs que se encontram em situação de vulnerabilidade social.

A ideia para o projeto surgiu a partir de visitas que as sócias fizeram ao Morro da Cruz, uma comunidade carente de Porto Alegre, para participar de um mutirão solidário. A partir do contato com a realidade o local surgiram as primeiras ideias para o negócio, que envolviam a possibilidade de um banco para microcrédito para os moradores do bairro. Com a relação mais direta junto à associação de moradores consolidou-se a ideia de que a empresa atuaria no desenvolvimento de produtos a partir da mão de obra destas artesãs.

A empresa B foi lançada oficialmente no final de 2014, mas o seu planejamento data de 2012. Nessa época, o casal de sócios estudava junto em uma faculdade de Design e compartilhava a ideia com mais dois colegas. A ideia inicial, de utilizar madeiras reaproveitadas de shapes de skates usados para produzir os 
A gestão de design de micro e pequenas empresas... sustentabilidade

WOLFF, F.; BENITES, P. R. G.

óculos de sol logo evoluiu para o conceito de revisitar excedentes da indústria moveleira local. O interesse pelo ecodesign e a vontade de aplicar na prática as metodologias projetuais que estudavam fez com que fundassem a empresa. Ao longo do caminho de estruturação da marca e produção dos primeiros protótipos os dois amigos deixaram o projeto, mas o casal de designers seguiu em frente e buscou aprofundar o conhecimento em duas áreas distintas e muito tradicionais: a marcenaria e a ótica.

Hoje a empresa conta com 3 designers estagiários para a produção, 2 sócios investidores responsáveis pelas áreas financeira e comercial, além dos dois sócios que se dividem entre a criação e o administrativo. A antiga sede de 35 metros quadrados ficou para trás e hoje a marca ocupa um espaço dentro de um dos galpões makers localizados no $4^{\circ}$ distrito de Porto Alegre, zona em processo de revitalização e foco de diversas iniciativas relacionadas à economia criativa na cidade.

A empresa C, localizada em Lajeado, desenvolve camisas com estamparia autoral, sem distinção de gênero, em tiragem limitada e com detalhes únicos em cada peça através da reutilização de excedentes da indústria têxtil em áreas como o punho e a gola dos produtos. A ideia para a marca surgiu em 2014, após uma viagem de um dos sócios de carro até a cidade de Machu Picchu, no Peru. $\mathrm{O}$ tempo gasto no trajeto serviu de combustível para reflexões que foram pautadas pelos contrastes sociais visualizados ao longo do caminho. Após quase 2 anos de incubação do projeto, a marca foi lançada oficialmente em 2015.

A equipe conta com dois sócios com formações em Administração e Design de Moda e uma rede produtiva que envolve mais 6 parceiros em diferentes etapas do processo. Apesar do pouco tempo de vida, a empresa já conquistou espaço, através do alcance obtido com a sua divulgação em mídias e canais de grande alcance. 


\section{A gestão de design de micro e pequenas empresas... sustentabilidade \\ WOLFF, F.; BENITES, P. R. G.}

O perfil geral da amostra é sintetizado no contato direto com sócios fundadores das três empresas contatadas, reflexo de uma caraterística marcante na amostra: a polivalência. Devido ao fato de todas as empresas contarem com equipes internas bastante reduzidas, entre duas e três pessoas, os sócios fundadores acabam acumulando funções diretivas e de gestão do negócio com funções de criação e de gestão produtiva. Dessa forma, ao mesmo tempo em que eram realizadas entrevistas com sócios diretores, também se estava entrevistando diretores de criação e de desenvolvimento de novos produtos, bem como gerentes de design destas empresas.

No que diz respeito ao perfil destas empresas estabelece-se uma convergência em relação ao tempo de existência, motivação, tamanho da equipe e estrutura interna. Trata-se de 3 empresas ainda jovens, fundadas entre 2013 e 2015. Este aspecto temporal relaciona-se com outras transformações sociais que se refletem nas escolhas profissionais destes jovens empreendedores.

Em geral, as três empresas surgiram da motivação de seus fundadores em minimizar o impacto de suas atividades produtivas sem abrir mão da vontade de entregar produtos de alto nível aos seus consumidores, conforme afirma a diretora de criação da empresa B: "A gente queria experimentar o que a gente acreditava do design que as vezes não era a coisa que a gente encontrava no mercado de trabalho." O resultado disto é um grupo de empresas com propósito criativo e preocupação com a sustentabilidade, como define o sócio-diretor da empresa C: “Então o que era a vontade de fazer uma marca de camisas acabou se transformando em um projeto bem maior, envolvendo propósito e tudo mais."

O tamanho das equipes também segue um padrão na amostra. As empresas contam, em geral, com dois sócios que se dividem em tarefas diversas no dia a dia do negócio, desde a criação até o administrativo. Como há uma otimização de processos visando um melhor aproveitamento de recursos, não existem equipes 
Projética, Londrina, v.11, n.1, p. 164-193, abril 2020

internas exclusivas para a atividade de design. Conforme afirma o sócio-diretor da empresa C: "A gente ainda não chegou a contratar ninguém, porque como a gente terceiriza tudo, toda a produção e a gente faz mais a gestão da marca mesmo." Assim como a empresa C, a empresa A também conta com toda a operação da produção terceirizada. No entanto, a relação estabelecida entre as artesãs e as sócias da empresa A se configuram mais como uma parceria do que como uma relação de fornecimento de mão de obra.

A exceção nesse quesito fica por conta da empresa B, que tem em sua equipe 3 estagiárias, com formação em design em curso, focadas exclusivamente na produção. O desafio enfrentado pela empresa B está mais relacionado à divisão de tarefas dentro de sua estrutura de pessoal, pois segundo os sócios, esta divisão era bem orgânica, mas acabou necessitando de uma divisão mais clara. O fato de a equipe ser composta apenas por designers resultado em falta de multidisciplinaridade o que faz com que algumas tarefas recebam menos atenção em uma abordagem mais orgânica como a anterior.

A formação das demais equipes, no entanto, não segue esse padrão. As empresas A e C aliam um designer e um profissional de outra área relacionada a negócios. No caso da empresa A, a sociedade é composta por uma designer de produto e uma bacharel em direito. Já a empresa C une uma designer de moda e um profissional formado em administração de empresas. Em ambos os casos há uma divisão mais clara entre o profissional de design relacionado às tarefas de gestão de criação e o profissional mais relacionado ao perfil de negócios como responsável pelas questões administrativas.

Em relação ao espaço físico também há variações entre as empresas entrevistadas. A empresa A ocupa uma sala dentro de uma casa colaborativa em Porto Alegre. Neste local há um espaço de showroom dos produtos e também área de trabalho para as duas sócias desempenharem suas funções administrativas. 


\section{A gestão de design de micro e pequenas empresas... sustentabilidade}

WOLFF, F.; BENITES, P. R. G.

A produção ocorre nas casas das próprias artesãs. A empresa B, por sua vez, está localizada em um espaço maker compartilhado com outra empresa que trabalha com marcenaria. Neste local, acontecem todas as atividades administrativas e produtivas da empresa. O espaço de produção conta com o equipamento necessário para desenvolver quase todo o ciclo produtivo dos óculos, com exceção de algumas etapas específicas. Já a empresa C passou boa parte de sua existência, com os sócios morando em continentes diferentes, no Brasil e em Portugal. As atividades administrativas eram realizadas em home office em horários alternativos pelos dois sócios. A produção é totalmente terceirizada e acontece nos ateliês de costura das parceiras responsáveis pelo processo.

O processos de design das empresas que compõem a amostra se mostraram bastante diferentes entre si. As diversas ênfases dadas em cada processo refletem os tipos diferentes de formações recebidas por seus responsáveis. Entre o empirismo da empresa $C$ ao academicismo da empresa $B$, aparece o colaborativismo da empresa A. Esta pluralidade no que diz respeito ao processo de design da empresa é o retrato deste perfil de empreendedores, com formações e vivências distintas, entendimentos diversos sobre um mesmo tema e muita vontade de imprimir o seu perfil no próprio negócio.

A equipe de design da empresa A, no que diz respeito ao processo, incorpora também as artesãs responsáveis pela produção, uma vez que o processo de desenvolvimento de novos produtos é orientado pelas técnicas que estas profissionais dominam. Sendo assim, para um novo produto ser lançado, ele deve primeiro passar pela avaliação de matéria-prima disponível, para então passar pela análise de capacidade produtiva da equipe de artesãs. Atualmente a produção é realizada por três artesãs principais, que guiam o processo e repassam o serviço a outras artesãs quando há uma demanda maior a ser produzida. 
Projética, Londrina, v.11, n.1, p. 164-193, abril 2020

O processo de design da empresa B é bastante fundamentado em metodologias projetuais devido ao fato de ambos os sócios possuírem a mesma formação em design. Dessa forma, ambos construíram um visão muito parecida sobre a maneira como os produtos são desenvolvidos e conseguem, ao mesmo tempo em que se dividem entre os projetos, colaborar mutuamente em etapas específicas de seus desenvolvimentos paralelos. O processo produtivo dos óculos, já bem estruturado, é realizado quase que integralmente dentro da empresa, tendo terceirizadas apenas algumas etapas que exigem alguma tecnologia específica, como a laminação da matéria prima e o corte a laser.

Já o processo de design da empresa C é bastante fluído e caracterizado pelo empirismo. Apesar de uma das sócias ser formada em design de moda, é o sócio formado em administração que lidera o processo de desenvolvimento de novos produtos. A trajetória do profissional e sua atuação em outras marcas, o credenciaram criativamente a gerenciar estes processos. A profissional do campo da moda está focada em gerenciar o processo produtivo, todo realizado externamente, e a relação com as costureiras terceirizadas.

Nas afirmações da SAGD relacionadas à dimensão do processo, ressalta-se a sequência de concordância de todos os entrevistados nas afirmações 2, 4, e 10, que tratam da organização do processo de desenvolvimento de produto, integração dos processos de design aos processos da empresa e integração da equipe de design em relação às demais equipes, respectivamente. Essa sequência indica que há um entendimento de integração do design nos processos da empresa, enquanto que há também a ideia que o design organizou esse processo de desenvolvimento de produtos e, por fim, a crença de que esta equipe de design está plenamente integrada às demais equipes da empresa, conforme a Figura 1. 
Figura 1 - Resultado SAGD: Processo

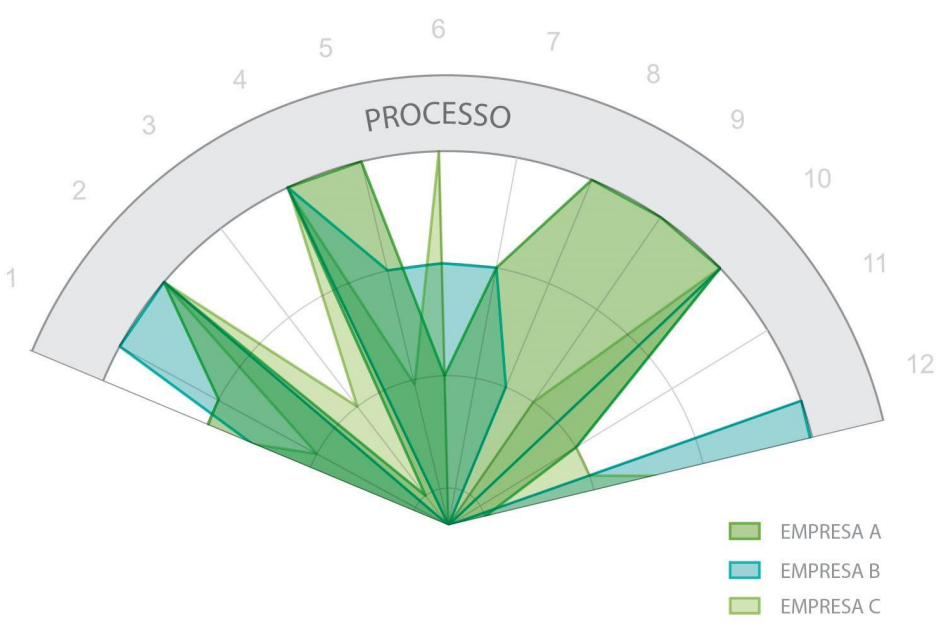

Fonte: Elaborado pelos autores.

Ao verificar o gráfico, é importante salientar que as respostas são plotadas no mesmo considerando o miolo do gráfico para pouca concordância com as variáveis e o extremo externo do gráfico como muita concordância com as variáveis. As cores indicam as três empresas e, ao analisar o gráfico é possível ver no que concordam e no que discordam entre si as empresas. Esta orientação é replicada a todos os gráficos apresentados nesta análise. No que diz respeito às competências de design, a amostra se apresenta diversa. Percebe-se que quanto mais profissionais com formação teórica em design, mais técnica é a abordagem e quanto menos profissionais com essa formação, mais empírica é o entendimento. A empresa B se destaca por apresentar um corpo crítico de design mais sólido, enquanto a empresa A e a empresa C estão muito mais relacionadas às trocas entre os atores e suas vivências práticas.

A equipe da empresa A conta com apenas uma profissional com formação em design que orienta todo o processo de desenvolvimento de produtos junto às artesãs. Apesar de este cenário parecer mais favorável a uma posição mais autônoma 
Projética, Londrina, v.11, n.1, p. 164-193, abril 2020

em relação às tomadas de decisão dentro do processo, o que se vê é uma relação de facilitação entre a designer e o restante da equipe. Dessa forma o design assume o papel de catalisador desse processo, onde a experiência e o conhecimento empírico de todos os envolvidos é levado em consideração. Os encontro semanais servem não só como momentos de conexão entre as responsáveis pelo desenvolvimento de produtos e as artesãs envolvidas no processo produtivo, mas também como um momento de aprendizado mútuo.

Em relação às competências da equipe responsável pelo design na empresa $\mathrm{B}$, há uma forte dinâmica entre os atores envolvidos. Apesar da organização interna entre desenvolvimento e produção, todos os profissionais relacionados ao processo de design vem de uma formação em design, o que contribui para um alto grau de interação entre estes atores. Os momentos de conexão são bem focados na questão de organização do processo de cada projeto, mas também há trocas em etapas específicas no decorrer destes projetos.

As competências de design são encaradas pela equipe da empresa C como algo natural, decorrente da prática vivenciada em experiências anteriores. $\mathrm{O}$ design é encarado com mais naturalidade como uma ferramenta para desenvolvimento de produtos e menos como um conjunto de conhecimentos teóricos. A equipe não possui uma rotina estabelecida de projeto e os momentos de conexão são marcados pela descontração, na grande maioria das vezes, em horários alternativos ao ritmo comercial.

As afirmações da SAGD, a partir da sentença 13, conforme ilustra a Figura 2, correspondem à dimensão de competência, onde destaca-se justamente a primeira questão que também obteve concordância total de todos os entrevistados e afirma que os designers são colaboradores importantes na empresa. A seguir, a questão 17 também merece ser citada, pois aborda a questão da atualização da equipe de design em cursos e faculdades e que obteve boa concordância geral. 
Figura 2 - Resultado SAGD: Competência

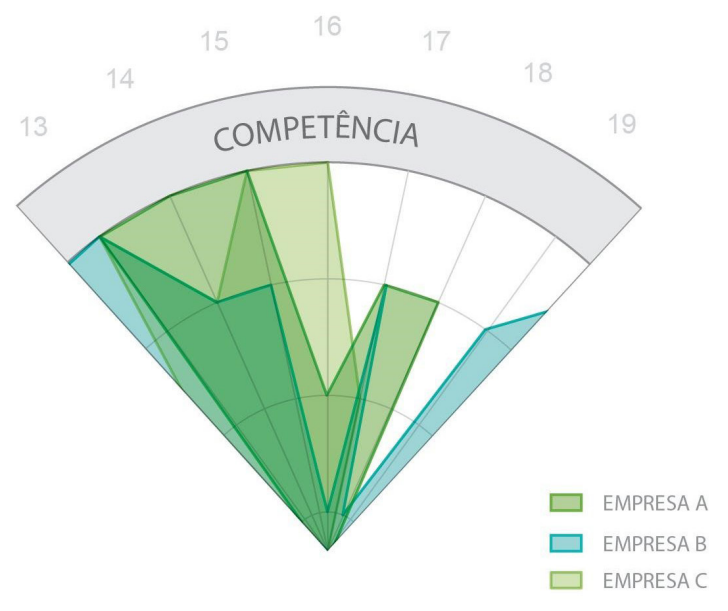

Fonte: Elaborado pelos autores.

De todas as dimensões da Gestão de Design, a estratégia de design é a mais incipiente no contexto das empresas entrevistas. Os processos de design são, em grande parte, adaptados à escala das micro e pequenas empresas devido à pouca disponibilidade de recursos financeiros e humanos. As competências de design, por sua vez, se mesclam entre conhecimentos habilidades e atitudes adquiridas no campo teórico e aqueles vivenciados na prática do dia a dia. Porém, no que tange à estratégia de design, há pouco planejamento e ainda menos rotinas de controle de desempenho.

Apesar de já ter participado de projetos focados de reutilização de matéria prima em parceria com grandes empresas, o planejamento de design da empresa A é ainda muito incipiente. Inicialmente, não houve nenhum tipo de planejamento estratégico, administrativo ou de produto para orientar os primeiros anos da empresa. No entanto, com o estabelecimento de um setor responsável pelo design na empresa, houve uma preocupação maior com as etapas iniciais do planejamento de novos produtos. Em 2016 a empresa recebeu uma consultoria fornecida por 
Projética, Londrina, v.11, n.1, p. 164-193, abril 2020

um programa de negócios de impacto que resultou em um reposicionamento e um planejamento estratégico para o ano de 2017 focado na venda business-tobusiness.

A estratégia de design da empresa B esteve bastante focada em colaborações de design durante os seus primeiros anos. Dessa forma, foram desenvolvidos produtos em parcerias com outras marcas, focando sempre na expertise de trabalhar com madeira proveniente de excedentes industriais. No entanto, houve uma mudança de foco e a empresa passou a trabalhar mais fortemente o aspecto comercial do business-to-business na venda para lojistas e para o segmento corporativo. Existem ferramentas estruturadas para controles de desempenho e a chegada de dois sócios investidores vem a contribuir ainda mais para o desenvolvimento das ferramentas de controle e planejamento.

A estratégia de design da empresa C segue a mesma linha da empresa: estratégia orientada por aspectos relacionados à experiência acumulada pelos empreendedores. Nunca houve um planejamento estratégico formalizado, tampouco uma rotina de controles administrativos estabelecida. Desde o início da estruturação da empresa houve uma preocupação maior em relação ao posicionamento da marca e sua comunicação, assim como no desenvolvimento dos produtos em si e seus processos criativos.

Com relação à inserção do design enquanto estratégia, conforme apresenta a Figura 3, destaca-se a total concordância da entrevistada nas afirmações número 21, 27 e 28 da SAGD. Na primeira destas afirmações, os entrevistados concordam totalmente com a ideia de que o design é entendido pela empresa como importante fonte na inovação de produto. Na segunda concordam com o fato de haver reuniões periódicas com as equipes envolvidas nos projetos de produtos. Enquanto na terceira afirmar concordar com o fato de que o design trabalha junto com as demais áreas da empresa no desenvolvimento de produtos. 
Figura 3 - Resultado SAGD: Estratégia

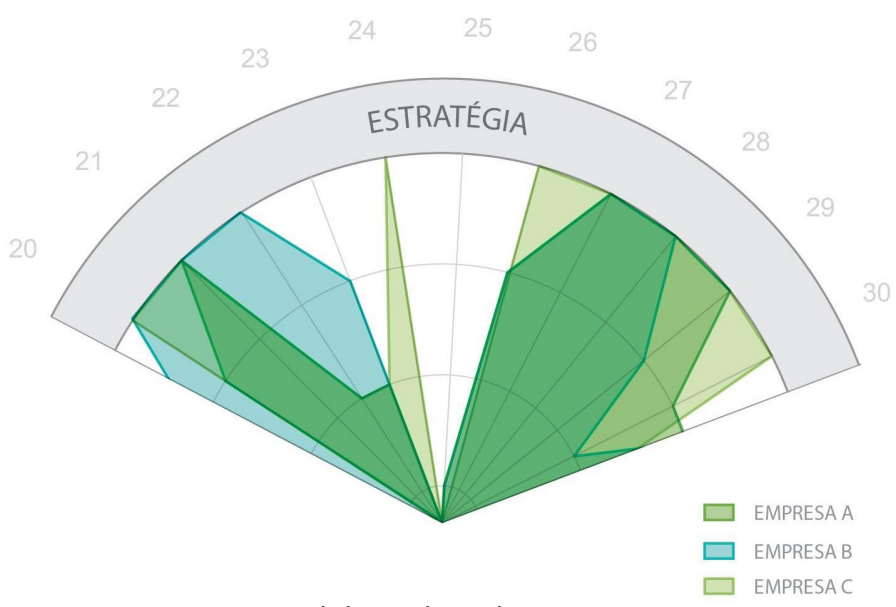

Fonte: Elaborado pelos autores.

O posicionamento em relação à sustentabilidade foi unanime entre todas as empresas desta amostra. Apesar de haver uma escala de intensidade nos discursos das marcas, percebe-se que este tipo de posicionamento é algo natural para estas empresas. Da sustentabilidade "por completo" ao "faça tudo o que puder para minimizar o impacto" todos os entrevistados sentem as mesmas dificuldades: tornar competitivo e lucrativo um negócio que se preocupa com o impacto do seu ciclo produtivo, algo ainda pouco comum no Brasil.

Em relação à sustentabilidade, analisada nesta pesquisa através das questões qualitativas, da primeira etapa do roteiro aplicado, a entrevistada da empresa A reforça este como o foco principal da atuação da empresa: "A gente tenta ser sustentável por completo [...] e a ideia é trabalhar sempre os três pilares, 0 ambiental, o econômico e o social". Apesar de o interesse inicial ter surgido através da questão social, hoje a empresa trabalha os três pilares da sustentabilidade através da valorização da mão de obra local, da geração de renda pelo estabelecimento de valores justo e da reutilização de matéria prima. 
Projética, Londrina, v.11, n.1, p. 164-193, abril 2020

A entrevistada da empresa A elenca o aspecto financeiro como o principal desafio: "A questão financeira também pesa a medida em que tentamos conciliar o valor justo de produção com o valor que o produto vai chegar no mercado." Além disso, há também a dificuldade de encaixar os resíduos disponíveis com as técnicas dominadas pelas artesãs.

A empresa B traz em seu DNA o interesse pelo ecodesign. Desde a ideação da empresa este conceito já era uma motivação para a atividade dos jovens designers. Hoje, eles se posicionam como uma empresa sustentável, mas deixam claro que não utilizam este aspecto como um diferencial competitivo e abordam a sustentabilidade como algo natural e intrínseco a qualquer projeto de design. 0 interesse em explorar mais o tema em suas divulgações surgiu da necessidade de explicar a origem da matéria prima e o processo produtivo dos seus produtos. $\mathrm{O}$ receio inicial de parecer "eco-chato" se transformou em confiança de se posicionar mais claramente de um jeito humano em um cenário cada vez mais focado em tecnologia e desempenho. Apesar da dificuldades relacionadas aos custos de matéria prima e produção, a empresa segue focada em seguir por esta linha e contribuir para a popularização do consumo consciente.

A empresa C adota um tom mais cauteloso ao falar sobre a sustentabilidade. Apesar de se posicionar como uma empresa com produtos sustentáveis, a empresa reforça que o seu objetivo é fazer tudo o que se pode fazer da maneira que causar o menos impacto. O sócio-diretor da empresa afirma que o seu objetivo é "tenta fazer com que toda a nossa cadeia de produção seja a mais correta possível". Ele acredita que as marcas devem se posicionar a esse respeito para contribuir para que este mercado se torne algo "comum e natural" a todas as pessoas. Entre as dificuldades apontadas pelo entrevistado está a dificuldade em transformar o grande esforço envolvido em um produção de pouco volume em algo com grande rentabilidade. $O$ principal motivo para isso, segundo ele, é o fato de que a sustentabilidade "ainda não é um diferencial competitivo". 


\section{A gestão de design de micro e pequenas empresas... sustentabilidade}

WOLFF, F.; BENITES, P. R. G.

A última das categorias, a que trata da colaboração foi a que obteve resultados mais homogêneos. Abordada através da etapa de questionamentos mais qualitativos, visto que não é foco da SAGD abordar este tópico, foi possível perceber que há uma uniformidade na maneira como estas micro e pequenas empresas encaram a colaboração. Novamente o aspecto relativo a limitação dos recursos que estes empreendedores tem disponíveis ganha força como propulsor para um comportamento mais aberto e receptivo a colaborações. Estas empresas desenvolvem parcerias com empresas em diversos formatos visando sempre o sucesso mútuo e a rentabilização de ambos os negócios. Trata-se de mais um reflexo desta forma de empreender motivada por um propósito maior, de bem estar geral e coletivo.

A empresa A trabalha fortemente a questão da colaboração desde a sua origem. Desde a própria formatação do processo produtivo, até os projetos em parceria com grandes empresas, a colaboração está no core business da empresa. Além disso, a participação em eventos também é frequente, sejam eventos culturais para disseminação de conhecimentos ou eventos comerciais em parceria com outras marcas locais.

A colaboração está bem presente no dia a dia da empresa B. O fato de estar localizada em um espaço compartilhado já insere a empresa e sua equipe e um ambiente de troca diária. Além disso, os eventos que a marca participa, como o Galpão Makers e a Open Design são como catalisadores deste movimento empreendedor e conectam diversos novos empreendedores. Destas interações surgem novas possibilidades de trocas de experiências, conhecimento e novas relações comerciais.

A empresa C teve como premissa em sua fundação sempre "tentar fugir do padrão". Com isso em mente, a empresa buscou formas alternativas de viabilizar os seus lançamentos de produtos. E esse conceito se estende desde a criação das 
Projética, Londrina, v.11, n.1, p. 164-193, abril 2020

estampas em colaboração com artistas em ascensão até os eventos de lançamento em parceria com bares e restaurantes locais. A vontade de colaborar é tanta que os responsáveis pela marca acabaram criando um evento de moda autoral para unir diversos projetos em um fim de semana que envolvia um momento de troca de conhecimentos com a oportunidade de comercializar produtos.

\section{CONSIDERAÇÕES FINAIS}

Foram selecionadas para compor a amostra, empresas que utilizam de recursos secundários na etapa de pré-produção de seus produtos, como forma de manifestação do foco destas empresas na sustentabilidade como parte integrante de suas estratégias. Todas as empresas selecionadas utilizavam de alguma forma matérias-primas oriundas de descartes e refugos de processos produtivo anteriores. A empresa A, por exemplo, pauta o seu processo de desenvolvimento de produtos pela questão dos resíduos da indústria têxtil, que se transformarão novamente em matéria prima neste novo ciclo produtivo. Já a empresa B, revisita os excedentes da indústria moveleira para produzir suas peças singulares. A empresa $C$, por sua vez, se aproveita de resíduos têxteis pós consumo disponíveis para garantir o tom exclusivo presente nos detalhes de seus produtos.

A relação direta com o segundo requisito de Vezzoli (2010) é bastante clara na atividade destas três empresas, o que já as caracteriza de alguma forma como preocupadas com o tema sustentabilidade. Com relação aos demais requisitos, no entanto, não há um direcionamento claro por parte das empresas. Há um entendimento sobre a importância de cada um destes momentos ao longo do ciclo de vida do produto, mas isto ainda não se reverteu em algum plano de ação prático. O foco principal ainda está bastante presente nos dois primeiros requisitos: minimização do uso de recursos e seleção de recursos e processos de baixo impacto ambiental. 


\section{A gestão de design de micro e pequenas empresas... sustentabilidade}

WOLFF, F.; BENITES, P. R. G.

Todavia, é correto afirmar que há, mesmo ainda de maneira empírica, uma preocupação com a otimização da vida dos produtos através de projetos pensados para gerar produtos de alta qualidade, assim como com a extensão da vida dos materiais, uma vez que não há misturas entre materiais que dificultem sua reciclagem na etapa pós consumo. A falta de foco na questão de facilitação de desmontagem reside no fato de que as empresas entrevistadas consideram que não necessitam dessa preocupação, uma vez que, já são entregues prontos para o uso. Certamente em algum momento o produto será descartado e este ponto pode ser estudado em pesquisas especificas com este foco.

É possível perceber também que há um bom entendimento por parte das empresas sobre os conceitos de sustentabilidade e sobre a maneira como o design pode contribuir para ela. Vezzoli (2010) afirma que o design para a sustentabilidade naturalmente contribui para o desenvolvimento sustentável por se tratar de uma prática de design, educação e pesquisa. Nesse sentido, todas as e marcas entrevistadas percebem, de alguma maneira, o design como uma forma de contribuição às pessoas, no sentido de fazer com elas se questionem sobre o objetivo que buscam em suas decisões de compras.

No entanto, existem dificuldades de se trabalhar com produtos com este foco. Estas dificuldades ecoaram nas falas dos três entrevistados e confirmam o pensamento de Pazmino (2007) que afirma que o design para a sustentabilidade é um processo abrangente e complexo, devendo contemplar viabilidade econômica, correção ecológica e equidade social. De todos estes fatores, sem dúvida alguma, o aspecto econômico foi o mais forte. As micro e pequenas empresas entrevistadas enfrentam dificuldades em tornar seus produtos competitivos em um cenário que não favorece a produção sustentável. Isso, em grande parte, é culpa dos elevados custos envolvidos na fabricação destes produtos. 
Projética, Londrina, v.11, n.1, p. 164-193, abril 2020

Apesar de todas as dificuldade no desenvolvimento dos negócios, os designers entrevistados se mostraram dispostos a continuar lutando para transformar essa realidade. Nesse sentido, a amostra se apresentou como um contraponto ao pensamento de Fry (2008) que critica o papel atual dos designers ao afirmar que não há uma real noção por parte destes profissionais sobre como o design pode construir ou quebrar estruturas. O grupo de designers entrevistados assumiu seu papel como conector entre indústria e mercado e desenhou uma nova forma de interagir entre pessoas e produtos, mais sustentável e consciente.

Em se tratando da gestão de design, é estabelecida uma relação entre o contexto de aplicação prática do design investigado nesta pesquisa e os conceitos propostos por Wolff (2012) em seu Modelo Conceitual de Gestão de Design. Este modelo aborda a inserção e integração do design nas organizações através de suas três dimensões (processo, competência e estratégia) analisadas através de duas lentes: estruturas e entendimentos. As estruturas possuem caráter objetivo em todas as dimensões, já os entendimentos estão relacionados a questões muito mais subjetivas. Este modelo de estrutura inter-relacionada permite que as dimensões e suas facetas influenciam umas às outras trazendo a teoria mais próxima à realidade gerencial.

No caso da amostra pesquisada, esta aproximação teoria e prática foi bastante importante. Nem todas as empresas entrevistadas possuíam um conjunto de conceitos teóricos bem constituído em relação ao design. O conhecimento empírico se mostrou muito presente em todas as três dimensões de inserção do design nestas empresas, tanto em processo, quanto em competência e também em estratégia. $\mathrm{O}$ fato de estas empresas possuírem estruturas enxutas se reflete também em seus entendimentos acerca do design.

Ao comentarmos sobre o design como processo, é importante termos em mente que segundo Wolff (2012) este pode ser referente ao desenvolvimento de 
um produto específico, como processo pontual, e também pode se tornar uma tarefa contínua desempenhada por uma equipe integrada a todos os processos de desenvolvimento de produtos de uma empresa. As estruturas das micro e pequenas empresas entrevistadas, conforme dito anteriormente, é enxuta. A disponibilidade de recursos mostrou-se um fator restritivo para quem está iniciando um negócio com este foco. Dessa forma, toda a infraestrutura, bem como o papel da equipe envolvida no negócio são bastante otimizadas a ponto de se utilizar-se ao máximo os seus potenciais.

O contraponto destas estruturas reduzidas é a possibilidade de se poder ter um método muito mais controlado e curto, com momentos de conexão mais frequentes e orgânicos, sem a necessidade da burocracia que envolve processos mais longos em grandes equipes. Apesar de necessitar de uma atenção maior a um maior números de detalhes, equipes enxutas tendem a ser mais integradas e dinâmicas, o que se mostra bastante positivo em um contexto empreendedor. De maneira geral, há um bom entendimento destas equipes sobre sua própria realidade e o fato de haver sempre um designer de formação entre os sócios contribui a inserção deste pensamento projetual no ambiente empresarial como um todo.

Quando falamos em design como competência devemos compreender a questão da competência como algo pertencente ao processo, mas também como um reflexo da definição do que é design em si por parte do designer como profissional. Dessa forma, pode-se compreender, também, como se gerenciar o design e qual será o papel dos profissionais desta equipe na estratégia e nos processos da empresa (MARTINS; MERINO, 2011). Este foi o ponto que a amostra se mostrou mais heterogênea. Apesar de se ter uma boa compreensão de design em toda a amostra, este entendimento se mostrou distinto em cada uma das entrevistas. 
Projética, Londrina, v.11, n.1, p. 164-193, abril 2020

No que diz respeito às competências de design, a amostra se apresenta em uma escala bastante ampla. Percebe-se que quanto mais profissionais com formação teórica em design, mais técnica é a abordagem e quanto menos profissionais com essa formação, mais empírico é o entendimento. A empresa B se destaca por apresentar um corpo crítico de design mais sólido, enquanto a empresa $\mathrm{A}$ e a empresa $\mathrm{C}$ estão muito mais relacionadas às trocas entre os atores e suas vivências práticas.

Em relação às competências de design enquanto estruturas, ficou claro que quanto maior o número de profissionais com formação em design dentro das equipes maior é o conjunto de habilidades, conhecimentos e atitudes disponíveis (RUAS; ANTONELLO; BOFF, 2005). No entanto, quando se avalia entendimentos, percebem-se maneiras bastante distintas de se entender e fazer o design por parte destas equipes. Há um contraste grande entre um academicismo com base teóricas reforçadas e um empirismo baseado nas experiências anteriores vividas pelos próprios atores. A riqueza da comparação reside no fato de que, nem um, nem outro, isoladamente, são por só respostas únicas e corretas. Quanto maior for a intersecção entre estes dois extremos, mais profunda será a contribuição da equipe para os processos e estratégias de design da empresa.

Ao se pensar em design como estratégia deve-se ter em mente que isto está relacionado às políticas da empresa, como forma de se gerar um plano de ação que gere vantagem competitiva (HENDERSON, 1989). Os entendimentos da amostra se mostraram bastante claro em relação às políticas de cada empresa, suas intenções de design e suas abordagens de design no que diz respeito ao desenvolvimento de produtos. No entanto, a avaliação das estruturas relativas a estratégia de design nas empresas pesquisas mostra que ainda há muito a se trabalhar nesse quesito.

Existem raros controles estratégicos por parte dos empreendedores, à exceção de alguns poucos feitos ainda em fase de planejamento de algumas 
A gestão de design de micro e pequenas empresas... sustentabilidade

WOLFF, F.; BENITES, P. R. G.

das empresas entrevistadas. Este tipo de controle não faz parte das rotinas administrativas destas empresas o que representa um certo perigo para a saúde do negócio a longo prazo. Este tipo de indicadores serve não só para avaliar a qualidade e a efetividade dos projetos já lançados, como também para projetar e orientar passos futuros.

Apesar de existir pontos a serem trabalhados em todas as dimensões, é na dimensão de estratégia que aparece a maior lacuna. De forma geral, percebe-se que os esforços destes empreendedores esteve muito mais focado nas questões práticas de design, relacionadas aos níveis táticos e operacionais do que na questão estratégica em si. O destaque positivo reside no fato de existirem designers em posições gerenciais em todas as empresas entrevistadas. Há a necessidade apenas de se concentrar os esforços já existentes nas questões táticas processuais também no nível estratégico.

Constata-se que a relação entre Gestão de Design e Sustentabilidade tem boas perspectivas para o futuro. Fica claro que a estruturação das ferramentas de Gestão de Design em todas as suas dimensões podem contribuir para abertura de espaço para o aspecto sustentável dentro das empresas. Além da estratégia empresarial, a aplicação correta da Gestão de Design permite aos negócios com foco em sustentabilidade potencializar seus valores de marca e tornar seus produtos ainda mais competitivos em um mercado cada vez mais dinâmico. 


\section{A gestão de design de micro e pequenas empresas... sustentabilidade WOLFF, F.; BENITES, P. R. G.}

9. RUAS, Roberto; ANTONELLO, Cláudia Simone; BOFF, Luiz Henrique (org.). Os novos horizontes da gestão: aprendizagem organizacional e competências. Porto Alegre: Bookman, 2005.

10. THACKARA, John. Plano B: o design e as alternativas viáveis em um mundo complexo. São Paulo: Saraiva, 2008.

11. TRUMMER, Juliane; LLERAS, Silvia. Reflections on design education in a changing world. Design Management Review, Boston, v. 23, n. 4, p. 14-22, 2012.

12. VEZZOLI, Carlo. Design de sistemas para a sustentabilidade. São Paulo: EDUFBA, 2010.

13. WOLFF, Fabiane. Gestão de design: modelo conceitual e sistemática de avaliação. Porto Alegre: UniRitter, 2012.

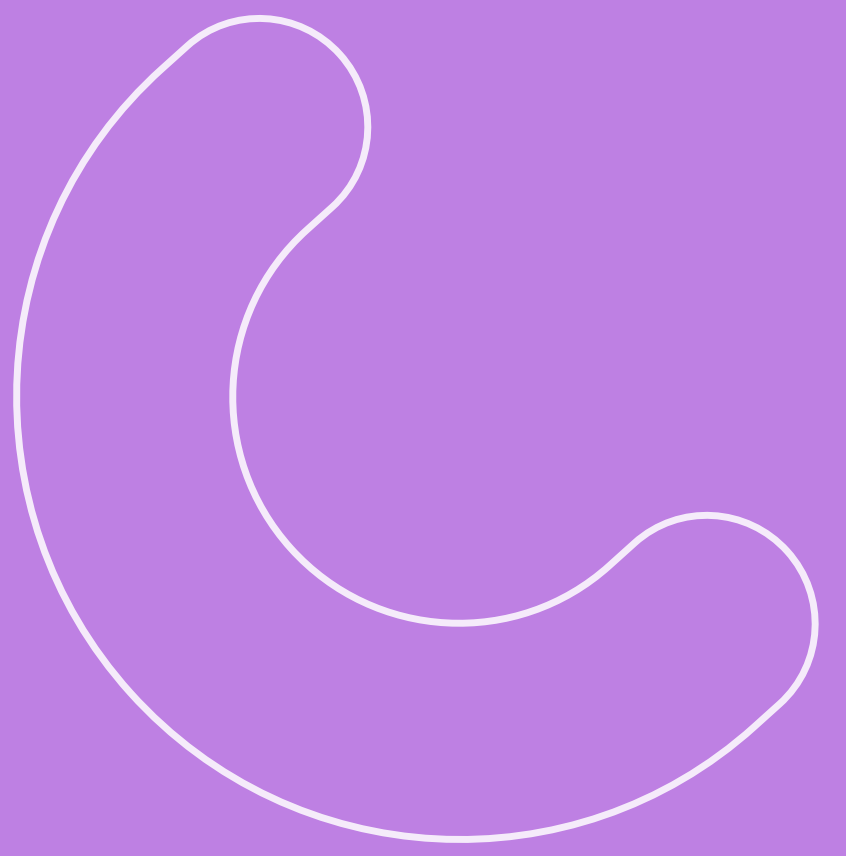

